\title{
Redes organizacionais e canais de distribuição no turismo
}

\section{Organizational networks and tourism distribution channels}

\author{
Bruno Martins Augusto Gomes (GOMES, B. M. A.) ${ }^{*}$
}

\begin{abstract}
RESUMO - É essencial para o sucesso de um setor econômico a compreensão por parte de seus agentes e planejadores, da dinâmica de funcionamento de sua cadeia produtiva. Mas pouco se tem discutido sobre a estruturação da cadeia do turismo, sobretudo acerca das ingerências dos distribuidores nesta. Por isso surge a importância de se discutir o papel dos canais de distribuição do turismo e a influência que a formação de redes organizacionais tem sobre estes. Para tanto foi elaborado um ensaio reflexivo no qual se discute as repercussões das redes organizacionais na distribuição do turismo. Este estudo teórico tem como contribuição, apresentar uma discussão recente, que são os canais de distribuição no turismo, colaborando para entender a atuação dos agentes na distribuição do mesmo. Ao final do trabalho são apresentadas questões que podem compor uma agenda de pesquisas complementares.
\end{abstract}

Palavras-chave: Turismo; Redes Organizacionais; Cadeia Produtiva; Canais de Distribuição.

\begin{abstract}
It's essential for an industry success understanding by their agents and planners, the dynamics of the supply chain. But little has been discussed about the structure of the tourism chain, especially about the influence of distribution. Hence its important discussing tourism distribution channels and the influence of organizational networks has on them. Thus, was developed a paper which discusses the influence of organizational networks on tourism distribution. This study contribution is to present a recent discussion about tourism distribution channels, contributing to understand the influence of agents in the distribution. At the end of the paper are presented issues that can make a research agenda.
\end{abstract}

Key words: Tourism; Organizational Networks; Production Chain, Distribution Channels.

\footnotetext{
* Bacharel em Turismo pela Universidade Federal de Ouro Preto (UFOP). Mestre em Administração pela Universidade Federal de Lavras (UFLA). Professor do Curso de Turismo da Universidade Federal do Paraná (UFPR). Endereço: Rua. Dr. Faivre, 405, Ed. Dom Pedro II, $3^{\circ}$ andar (Centro). CEP: 80060-140 Curitiba - PR (Brasil). Telefone: (41) 3360-5050. E-mail: gomesbma@ufpr.br
} 


\section{INTRODUÇÃO}

Apesar de o turismo obter maior expressividade nos últimos anos, é essencial para sucesso do setor, a compreensão da dinâmica de funcionamento de sua cadeia produtiva. Assim se evita que um reduzido número de agentes coordene a cadeia de acordo com os seus interesses, negligenciado as necessidades dos vários outros agentes envolvidos. Fato este já comum em outros setores econômicos.

Para Martínez (2005) as pesquisas que abordam a forma como os atores interagem entre si, são muito importantes para o estudo do funcionamento do turismo, pois permitem não apenas identificar os atores como também à relevância de cada um no sistema turístico. Harland (1996) realizando uma pesquisa comparativa na cadeia automotiva no Reino Unido e na Espanha, buscou verificar se havia evidência de que as redes afetavam o desempenho da cadeia. $\mathrm{O}$ autor identificou que o mau relacionamento entre os membros da cadeia, portanto, a ausência de integração entre os mesmos, influenciava a satisfação do cliente.

Na cadeia do turismo há uma dependência entre os agentes, pois como coloca Gomes (2008), ela não é linear, com cada agente exercendo a sua função isoladamente, como em outros setores da economia. Há uma atuação conjunta de vários agentes e com a participação do consumidor no momento da prestação dos serviços. Assim, a estrutura de produção do turismo é composta basicamente pelos agentes locais e agentes externos, assim descritos:

- Agentes locais, que são os meios de hospedagem, restaurantes, empresas de transportes, entretenimento, agências de receptivo;

- Agentes externos, que incluem as operadoras de turismo e as agências de viagens; e os agentes de apoio, que são bancos, hospitais, postos de combustíveis, supermercados, dentre outros serviços.

Após fecharem acordos com os agentes locais as operadoras de turismo distribuem este produto turístico por meio de contratos com as agências de viagens.

Dessa forma, esse ensaio reflexivo tem como objetivo tecer considerações acerca da estruturação dos canais de distribuição no turismo e a influência da formação de redes nestes. Para tanto foi realizada uma revisão de literatura utilizando livros e periódicos de autores considerados referência nos temas tratados. O ensaio aborda 
inicialmente os canais de distribuição, enfatizando o papel dos intermediários. Em seguida são debatidas as diversas formas de rede que as organizações podem se estruturar. Então é discutida a distribuição do turismo, considerando a influência das redes organizacionais nesta. Em sua parte final, apresentam-se considerações sobre o tema tratado e a indicação de uma pauta com possíveis abordagens para pesquisas futuras.

\section{CANAIS DE DISTRIBUIÇÃO}

Os canais de distribuição estão por detrás de todo produto e serviço que consumidores e intermediários adquirem. Coughlan et al. (2002) explicam que existem muitas organizações envolvidas nas atividades dos canais de distribuição, sendo cada uma dependente das demais para desempenhar sua função correspondente no funcionamento dos mesmos. Os processos dos canais de distribuição buscam disponibilizar um produto ou serviço para uso ou consumo. Portanto, busca-se satisfazer os usuários finais no mercado. Assim, as decisões sobre quais canais de distribuição e suas respectivas características desempenham um papel de importância estratégica na presença e no sucesso de uma empresa no mercado.

Portanto podem-se definir os canais de distribuição como "um conjunto de organizações interdependentes envolvidas no processo de disponibilizar um produto ou serviço para uso ou consumo" (COUGHLAN et al., 2002, p. 20).

Nos canais de distribuição que contêm intermediários ou distribuidores há uma facilitação da relação entre produtores e usuários finais. Os distribuidores, além de disponibilizar produtos para os usuários finais oferecem: aconselhamento; crédito e auxílio financeiro, o que permite aos clientes usar os produtos em seus negócios antes de pagar por eles; sortimento, permitindo ao usuário final a conveniência de poder escolher entre vários produtos em mesmo local e, finalmente, o processamento dos pedidos dos clientes, repassando-os para os atores locais. Esta última característica possibilita aos distribuidores reunir informações do mercado em função da proximidade que têm com os clientes. Assim, os usuários finais não sabem ao certo onde encontrar os produtos ou serviços que procuram, enquanto os produtores não sabem ao certo como 
alcançar os usuários finais. Portanto, surgem os distribuidores reduzindo as incertezas, facilitando e ampliando as transações. Dessa forma, sem intermediários de canal, cada produtor teria de interagir com cada comprador em potencial para criar todos os intercâmbios possíveis de mercado.

A Figura 1 ilustra estas colocações ao representar uma transação na qual se tem os fornecedores (quatro retângulos na parte superior), os distribuidores (dois retângulos no meio) e os consumidores (dez retângulos na parte inferior). A figura evidencia a importância dos intermediários na redução da complexidade desse sistema de intercâmbio, facilitando as transações. Os intermediários também podem agregar valor ao produtor, pois quando possuem boa reputação esta estará associada ao produto que distribuem.

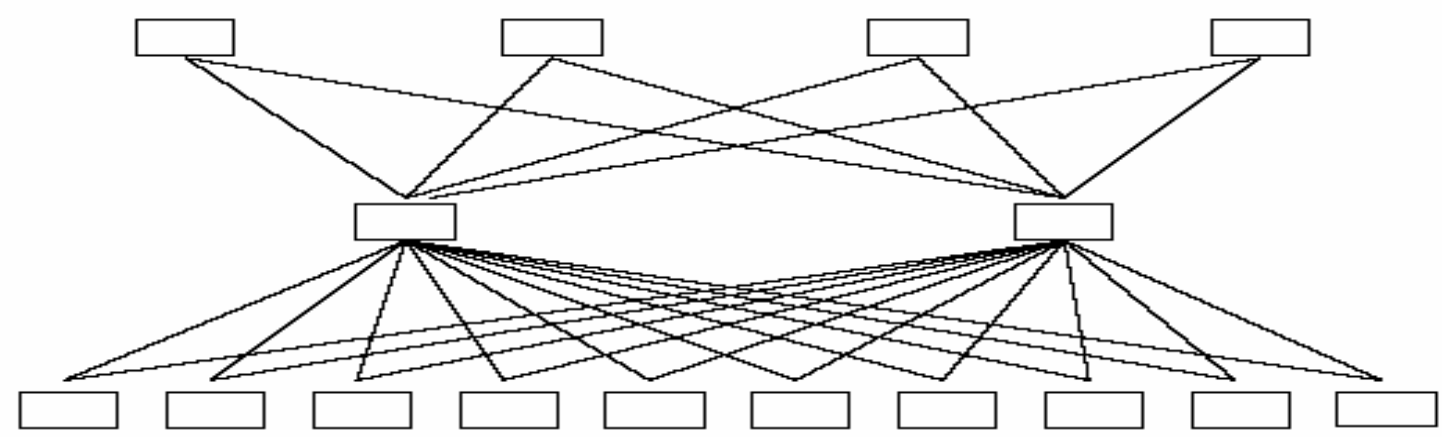

FIGURA 1: CONTATO ENTRE PRODUTORES E CONSUMIDORES ATRAVÉS DOS DISTRIBUIDORES

FONTE: COUGHLAN ET AL. (2002, p. 24)

Rosenblom (2002) coloca que os distribuidores estão assumindo um maior poder. De acordo com este autor, esse fato está relacionado primeiramente ao aumento no poder de compra de muitos distribuidores devido ao crescimento das fusões e aquisições. $\mathrm{O}$ aumento no poder dos distribuidores também se deve à utilização de avançadas tecnologias, o que os têm feito mais exigentes na seleção de produtos e serviços a intermediar.

Contudo, as demais partes da cadeia devem estabelecer contratos e parcerias, evitando assim que surjam barganhas e descumprimento de normas nesses processos. Coughlan et al. (2002) destacam a importância de se projetar o canal considerando: o segmento de mercado que se está analisando e as fontes de poder e dependência entre os membros do canal. 


\section{REDES ORGANIZACIONAIS}

O conceito de redes apresenta múltiplos significados de acordo com a área do conhecimento em que é abordado. Segundo Lazzarini et al. (2001), nos estudos de administração e economia as análises de redes buscam explicar a organização e o funcionamento de setores econômicos. Nessa perspectiva, Zylbersztajn e Farina (2003) conceituam as redes como um arranjo institucional complexo e multi-organizacional desenhado para coordenar as transações entre agentes, a fim de criar e agregar valor às organizações envolvidas.

A rede é caracterizada pela condição de autonomia das organizações que a compõem e pelas relações de interdependência que estabelecem entre si. É um espaço no qual se produz uma visão compartilhada da realidade, se articulam diferentes tipos de recursos e se conduzem ações de forma cooperada, necessitando de uma coordenação orientada ao fortalecimento dos vínculos de confiança e ao impedimento da dominação (Migueletto, 2001).

Para Vale (2004) as redes se distinguem em três tipos: Redes Setoriais de Empresas de Objetivo único, Redes Organizacionais de Interesse Amplo e Redes Empresariais de Interesse Amplo, cada qual contendo as seguintes particularidades:

- Redes Setoriais de Empresas de Objetivo Único: são associações de empresas, do mesmo setor de atividades, com o propósito de resolver algum problema específico, associado à produção ou ao mercado.

- Redes Organizacionais de Interesse Amplo: constituídas por associações formadas por diferentes agentes produtivos, localizados em um mesmo território, tais como empresas, instituições governamentais, entidades de apoio empresarial, agências de financiamento, centros de pesquisa e desenvolvimento tecnológico. Estão voltadas para a construção de estratégias cooperadas de inserção do território na economia nacional.

- Redes Empresariais de Objetivos Múltiplos: associações de empresas de atividades afins, localizadas no mesmo espaço geográfico, que buscam, em geral, a construção de estratégias cooperadas de produção e inserção mercadológica, através de processos de adaptação e especialização produtivas e/ou negociações coletivas. 
Segundo Milaneze e Batalha (2004), dentre as vantagens obtidas por meio do relacionamento cooperativo entre os agentes estão:

- Melhor aproveitamento dos recursos,

- Compartilhamento de riscos,

- Melhores condições de explorar novos mercados,

- Realização de atividades em conjunto (minimizando esforços),

- Maior poder de negociação com agentes externos,

- Maior acesso à informação,

- Agregação de maior valor aos produtos,

- Maior facilidade na obtenção de crédito.

Omta et al. (2001) colocam que na teoria de redes as formas de colaboração não se baseiam apenas em motivações econômicas, mas poder e confiança também são conceitos chaves nessa abordagem. O'Toole (1997) acrescenta que as redes podem até envolver ligações de autoridade, mas essencialmente se baseiam em articulações que estão voltadas para o interesse comum. Powell e Smith-Doerr (1994) apud Vale (2006) ${ }^{1}$ destacam que uma pesquisa de campo sobre redes, voltada para o tema governança, pode gerar insights sobre como os vínculos são criados e mantidos, que recursos fluem e principalmente quais as conseqüências destes vínculos.

Neste sentido, as redes organizacionais constituem um mecanismo de atuação para os agentes locais do turismo, especialmente para aqueles com um menor poder de negociação dentro da cadeia.

\section{A DISTRIBUIÇÃO NA CADEIA PRODUTIVA DO TURISMO}

Esta discussão sobre distribuição no turismo se fundamenta em transações mais eqüitativas. Assim como coloca Baggio et al. (1983) no trecho a seguir, analisando outro setor produtivo, é relevante refletir acerca da influência dos distribuidores do turismo sobre os demais membros da cadeia.

\footnotetext{
1 POWELL, W. P.; SMITH-DOERR, L. Networks and economic life. In: SMELSER, N. J.; SWEDBERG, R. (Ed.). The handbook of economic sociology. Princeton, NJ: Princeton University, 1994. p. 268-403.
} 


\begin{abstract}
A Bunge y Born é uma das cinco maiores empresas que dominam o mercado de grãos no Brasil. O sojicultor, para produzir, necessita de financiamento para custear a lavoura. O dinheiro vem através do Banco do Brasil S. A. com juros que, por sua vez, pediu emprestado com juros, dentre outros bancos, ao Banco Francês e Brasileiro que é da Bunge y Born. Com o dinheiro, o produtor irá comprar insumos. Se comprar adubos Serrana da Quimbrasil estará devolvendo o dinheiro para a Bunge y Born, pois ela é dona da Quimbrasil. Feita a produção, o produtor ou vende através de sua cooperativa que por sua vez irá vender para as indústrias, na maioria dos casos, ou vende diretamente às indústrias. Se vende a Samrig, estará vendendo para a Bunge y Born por um preço estabelecido por pressão da própria multinacional em Chicago, nos E.U.A. De posse do dinheiro, o produtor resolve vestir a família e realiza algumas compras no supermercado. Caso compre as malhas Santistas, óleo Primor ou margarina Primor estará devolvendo o dinheiro para a Bunge y Born já que são suas as indústrias que fabricam esses produtos. Caso sobre algum dinheiro e o produtor decida construir algum galpão, casa, ou fazer alguma melhoria em sua propriedade e comprar cimento Serrana e após, tintas Coral para pintar o que construiu, estará novamente devolvendo dinheiro à Bunge y Born, pois ela também é dona dessas indústrias (BAGGIO et al., 1983 apud ALENCAR, 2001, p. 17)².
\end{abstract}

Por sua vez, no turismo, a cadeia produtiva tem como matéria-prima os atrativos turísticos naturais ou culturais, em torno dos quais são ofertados serviços pelos agentes locais. As operadoras de turismo distribuem este produto turístico mediante acordos de pagamento comissionado junto aos agentes locais.

As operadoras podem comercializar este produto turístico ou repassar o direito de comercialização às agências de viagens por meio de acordos de pagamento comissionado. Então, o turista irá comprar o produto turístico nas agências de viagens ou poderá optar por fazê-lo por conta própria, diretamente com os agentes locais. O consumo do produto turístico ocorrerá com o deslocamento do turista até a região turística, auxiliado pelos serviços de apoio.

Contudo, a estruturação da cadeia do turismo varia de acordo com o segmento e os valores predominantes entre os agentes locais. Nesse sentido, Beni (2001) coloca que o turismo pode ser estratificado em turismo de elite, turismo de massa e turismo social. O turismo de elite é caracterizado pelo autor como o turismo realizado por uma classe social economicamente privilegiada, que descobre e desenvolve novos pólos de atração turística. Assim cria-se a necessária infra-estrutura básica e turística, em pequena escala, tendo um gasto-dia maior que nas demais categorias de turismo e permanecendo um tempo mais longo nos núcleos receptores.

\footnotetext{
${ }^{2}$ BAGGIO, A. P.; GRISON, A. J.; BRUM, A. L.; BELLATO, D.; MARQUES, M. O.; VERZA, S. B.; FRANTZ, T. R.; BASSO, D. Elementos de Cooperativismo e Administração Rural. Ijuí: Fidene/Unijuí, 1983.
} 
O turismo de massa é caracterizado por Beni (2001) como uma expressiva quantidade de turistas que utilizam, em larga escala, equipamentos e serviços turísticos, tendo um gasto-dia moderado, usufruindo de transportes mais econômicos e normalmente incluídos nos pacotes comercializados pelas agências de viagens.

No outro extremo há o turismo alternativo. Adotou-se a terminologia turismo alternativo para se referir a uma forma de turismo oposta ao turismo de massa. Porém, percebe-se que este segmento difere da definição de turismo de elite proposta por Beni (2001) pois, não necessariamente, o turista alternativo tem elevado poder aquisitivo. Este turista também pode ser de classe média. Ser intelectualmente curioso é a caracterítica que o destaca, como define Neal (2000) citando Plog (1987) ${ }^{3}$. Esse fato o faz buscar locais que fogem das rotas do turismo de massa e conhecê-los detalhadamente.

Assim como coloca Macleod (2002, p. 167), deve-se salientar que há ambiguidade no conceito de turismo alternativo. Dessa forma, adotar-se-á neste trabalho a terminologia turismo de massa, de acordo com a abordagem de Beni (2001), e turismo alternativo para se referir a um turismo caracterizado:

- Pela busca por dissociar-se do turismo de massa;

- Pelo número reduzido de turistas nas viagens, o que possibilita maior interação com a população local;

- Pela busca, por parte do turista, de conhecer mais detalhadamente os locais visitados; e

- Pelo uso de equipamentos turísticos de pequena escala.

Conforme demonstrado na Figura 2, no turismo alternativo, os canais de distribuição se estruturam na forma de redes, principalmente entre agências de receptivo e empresas de meios de hospedagem. O produto turístico é organizado pelos atores locais e os consumidores o adquirem diretamente com estes. Portanto não há influência das operadoras. Quando muito, existem algumas agências que colaboram nesta comercialização, mas com um poder de influência significativamente menor sobre os atores locais.

\footnotetext{
${ }^{3}$ PLOG, S. C. (1987). Understanding psychographics in tourism research. In: RITCHIE, J. R. B.; GOELDNER, C. R. (Eds.) Travel, Tourism and Hospitality Research: a Handbook for Managers and Researchers. John Wiley \& Sons, New York, p. 203-213.
} 


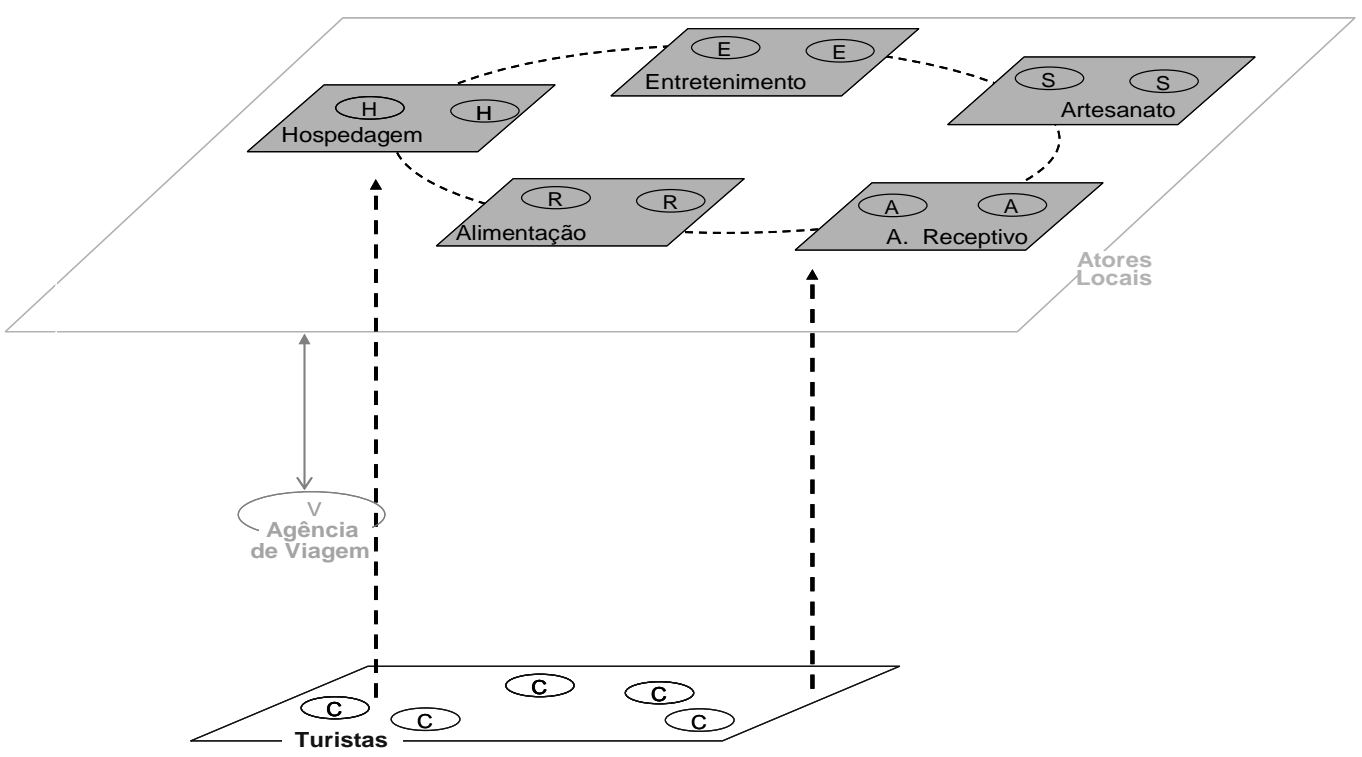

FIGURA 2: DISTRIBUIÇÃO NO TURISMO ALTERNATIVO

Elaborado pelo autor

Estas parcerias podem ocorrer também entre atores locais e parceiros externos que possuem comunicação direta com o público-alvo, por exemplo, propagandas em estabelecimentos comerciais amplamente freqüentados pelo turista potencial. Pequenas pousadas do sul de Minas Gerais utilizam essa estratégia, na medida em que divulgam seus produtos em restaurantes de São Paulo, que são freqüentados pelo seu públicoalvo. Além dessa estratégia de divulgação, as pousadas oferecem aos hóspedes serviços de transporte São Paulo - Sul de Minas - São Paulo. Existem também os contratos entre os atores locais e agências de viagens localizadas nas regiões emissoras. Essa situação pode ser visualizada entre pousadas de Arraial d'Ajuda, sul da Bahia, que fazem contratos com agências de viagens de São Paulo e outros grandes centros, a fim de que estas vendam suas hospedagens.

Já no turismo de massa, o turista busca predominantemente adquirir todos os serviços turísticos através de uma agência de viagem. Por isso os canais desse segmento estão estruturados através de contratos entre operadoras de turismo, agências de viagens e atores locais (principalmente meios de hospedagem e agências de receptivo na região receptora).

Como se pode observar na Figura 3, as operadoras de turismo (representadas pela letra O), utilizando o seu poder de barganha (representado pelas setas largas), 
formatam produtos turísticos a partir de contratos com os atores locais (hospedagem, entretenimento, alimentação e receptivo). Estes produtos chegam aos consumidores (turistas, representados pela letra C) por meio das agências (representados pela letra V), que os comercializam mediante contratos com as operadoras. Assim, o turista encontrará todos os serviços em um só ponto de compra, a agência de viagem. Portanto a figura evidencia que, apesar de serem em reduzido número, as operadoras facilitam a comunicação dos atores locais com os consumidores e também exercem considerável influência na cadeia.

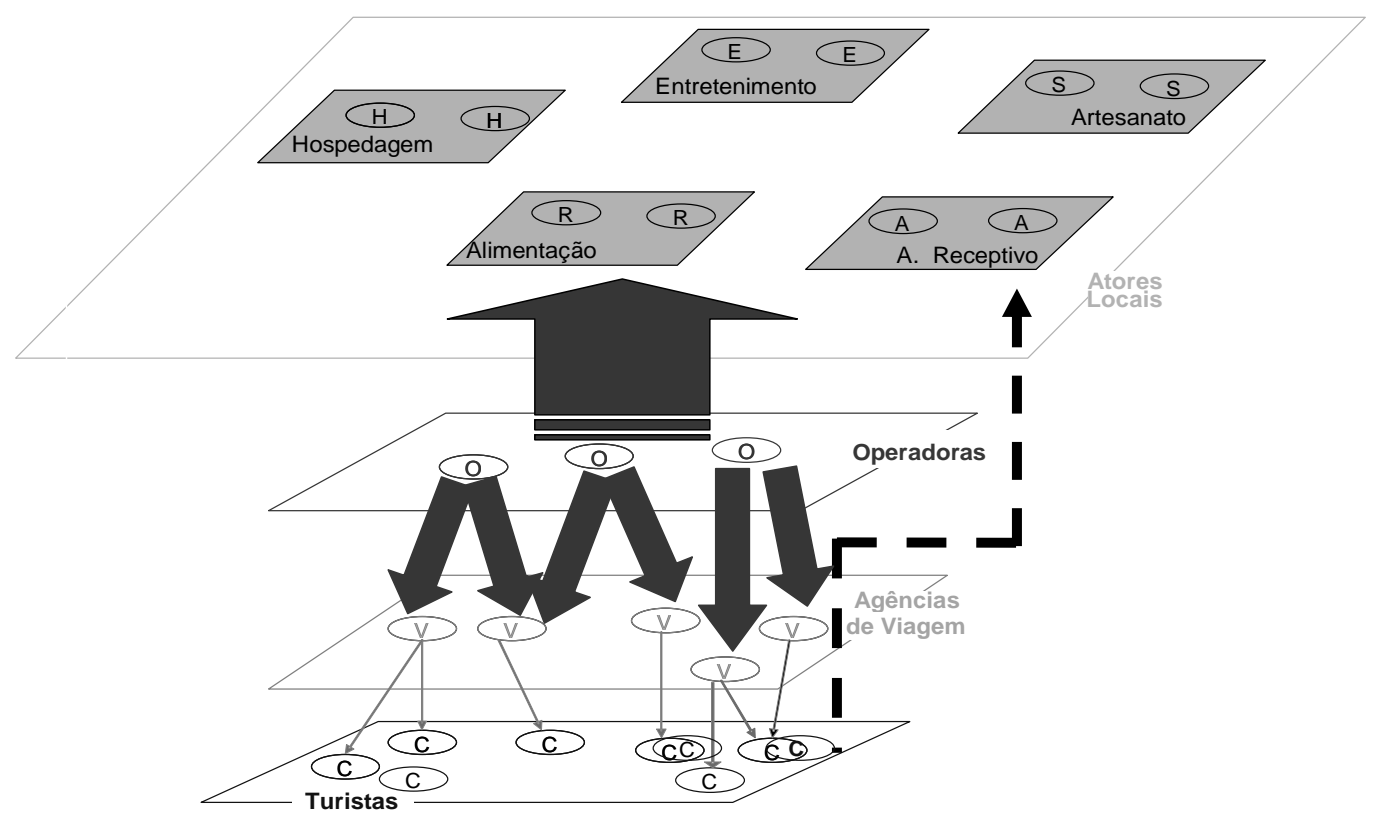

FIGURA 3: DISTRIBUIÇÃO NO TURISMO DE MASSA

Elaborado pelo autor

Para ilustrar, pode-se citar o exemplo de grandes operadoras de turismo que fecham contratos com hotéis e agências de receptivo nas capitais situadas no litoral do nordeste brasileiro. Dessa maneira formatam pacotes que são comercializados através de contratos estabelecidos entre a operadora e agências de viagens localizadas em várias cidades do país. Como coloca Rosenblom (2002), as organizações maiores têm maior capacidade de influenciar as ações dos outros membros do canal. O poder dos intermediários no canal de distribuição do turismo de massa, especialmente das operadoras, está relacionado ao poder de compra.

Por isso acredita-se que, se as organizações da região receptora, ao formarem uma rede, passam a definir quem serão distribuidores de seu produto turístico e como 
esses deverão distribuí-lo. Contudo, caso isso não ocorra, elas tendem a ser dominadas pelas operadoras, transformando um turismo alternativo em turismo de massa.

Deve-se destacar que o poder de compra das operadoras influencia não só as negociações com os atores locais como também com as agências de viagens, o que é demonstrado na Figura 3 por meio da espessura das setas. Assim, há evidências de que, cada vez mais, a determinação do preço e forma de exploração de destinações turísticas se concentram sob domínio das operadoras, ficando em segundo plano as necessidades das populações receptoras.

A forma como o turismo alternativo é distribuído é benéfica, pois poupa os atores locais do poder oriundo dos contratos com as agências de viagens. Contudo, nessa modalidade os atores locais têm suas responsabilidades e riscos aumentados, pois com freqüência, não conhecem o mercado em termos de experiência em distribuição, característica na quais as operadoras e agências de viagem são especialistas. As operadoras, por meio de contratos com agências de viagens em várias localidades, possibilitam a cobertura de mercado amplo.

No turismo alternativo, por ser frequentemente distribuído pelos próprios atores locais, há um maior sentimento de solidariedade. Estes atores ao trabalharem na forma de redes visam não só o lucro, mas também uma contrapartida futura que pode ser, por exemplo, o êxito turístico da região em que se localizam.

Assim, pode-se considerar que se torna evidente que, ao se estudar canais de distribuição no turismo, é essencial levar em conta a diferenciação da distribuição no turismo de massa e no turismo alternativo. No turismo alternativo, diferentemente do turismo de massa, a distribuição tende a se pautar nas redes. Nesta perspectiva também se pode afirmar que a distribuição pautada nas redes entre os agentes locais gera maiores benefícios a estes, pois os tornam menos vulneráveis ao poder dos distribuidores.

\section{CONSIDERAÇÕES FINAIS}

Diante do expressivo crescimento do turismo nas últimas décadas, percebe-se a importância de compreender como ocorrem as relações entre os agentes na cadeia do setor. Os distribuidores do turismo são importantes, pois facilitam a comunicação dos 
atores locais com o consumidor. Contudo, em função de sua porcentagem de compra demonstrada pelas operadoras de turismo, o poder está presente na relação destas com os agentes locais. Assim, apesar de alguns destinos resistirem, cada vez mais, a determinação do preço e forma de exploração de destinações turísticas se concentram sob domínio das operadoras, ficando em segundo plano as necessidades dos agentes locais.

Acredita-se que no turismo a articulação dos agentes locais em rede, constitui um mecanismo de coordenação que lhes permitirá definirem em suas negociações junto aos agentes externos (que detêm maior poder), o que pode ser feito, como pode ser concretizado e quem deve fazer o que.

É essencial que estudos sobre canais de distribuição do turismo busquem identificar se há um ator que coordena a distribuição. Em seguida, deve-se buscar verificar se o poder existente nessa coordenação é positivo ou negativo para os coordenados. Caso verifique-se que é negativo percebe-se a importância de propor aos coordenados formas de distribuição que minimizem ou, se possível, eliminem a dependência destes em relação ao ator que coordena.

Por isso, considerando as diferenças de articulação dos agentes locais em núcleos receptores de turismo, estudos futuros devem:

- Descrever como se estrutura a cadeia produtiva do turismo em núcleos receptores.

- Descrever e analisar os principais atributos que caracterizam as transações entre os agentes na cadeia do turismo.

- Verificar as influências da formação de redes entre os agentes locais na coordenação da cadeia do turismo.

- Verificar os efeitos, positivos e negativos, que a estrutura de coordenação predominante na cadeia do turismo gera para os agentes.

- Analisar o papel do Estado na estruturação do turismo enquanto representante dos atores locais.

- Apresentar estratégias relacionadas à distribuição do produto turístico, que gerem benefícios para o maior número de agentes envolvidos.

A partir de tais estudos acredita-se que conhecimentos oriundos destas pesquisas contribuirão para o progresso do setor de turismo, apresentando estratégias, que ao 
serem aplicadas pelos planejadores do setor, possibilitarão uma estruturação da cadeia com canais de distribuição que beneficiem um número maior de agentes nas regiões receptoras.

\section{REFERÊNCIAS}

ALENCAR, E. Complexos Agroindustriais. Lavras: UFLA/FAEPE, 2001.

BAGGIO, A. P.; GRISON, A. J.; BRUM, A. L.; BELlATO, D.; MARQUES, M. O.; VERZA, S. B.; FRANTZ, T. R.; BASSO, D. Elementos de Cooperativismo e Administração Rural. Ijuí: Fidene/Unijuí, 1983.

BENI, M. C. Análise Estrutural do Turismo. São Paulo: Editora Senac, 2001.

COUGHLAN, A . T.; ANDERSON, E.; STERN, L. W.; EL-ANSARY, A. I. Canais de Marketing e Distribuição. Porto Alegre: Bookman, 2002.

GOMES, B. M. A. Políticas Públicas e as Transações em Regiões Turísticas. São Paulo: All Print, 2008.

HARLAND, C. M. Supply Chain Management: Relationships, Chains and Networks. British Journal of Management, v. 7, Special Issue, March 1996.

LAZZARINI, S. G.; CHADDAD, F. R.; COOK, M. Integrating supply chain and network analyses: the study of netchains. Journal on Chain and Network Science, v. $1,2001$.

MACLEOD, D. Turismo Alternativo: uma análise comparativa do seu significado e do impacto por ele causado. In: THEOBALD, W. Turismo Global. São Paulo: Editora SENAC São Paulo, 2002.

MARTÍNEZ, A. J. J. Aproximação à Conceituação do Turismo a Partir da Teoria Geral de Sistemas. In: TRIGO, L. G. G. (Ed.) Análises Regionais e Globais do Turismo Brasileiro. São Paulo: Roca, 2005.

MIGUELETTO, D. C. R. Organizações em Rede. Dissertação (Mestrado em Administração Pública) - Fundação Getúlio Vargas. Escola Brasileira de Administração Pública, Rio de Janeiro, 2001.

MILANEZE, K. L. N.; BATALHA, M. O. Competitividade em rede de empresas: proposta de ferramenta que permite analisar a importância de fatores relacionados à competitividade nas redes. In: XI SIMPEP (SIMPÓSIO DE ENGENHARIA DE PRODUÇÃO), 2004, Bauru. Anais... Bauru, 2004. 
NEAL, J. D. The Effects of Different Aspects of Tourism Services on Travelers Quality of Life: model validation, refinement, and extension. Tese (Doutorado em Filosofia). Virginia Polytechnic Institute and State University, Virginia, EUA, 2000. Disponível em: <http://scholar.lib.vt.edu/theses/available/etd-0413200005470052/unrestricted/etd11.pdf>. Acesso em: 20/03/2010.

OMTA, S.W. F.; TRIENEKENS, J. H.; BEERS G. Chain and Network Science: a research framework. Journal on Chain and Network Science, v.1, n. 1, 2001.

O'TOOLE Jr., L. J. Treating Networks Seriously: Practical and Research-Based Agendas in Public Administration. Journal Article Public Administration Review, v. 57, 1997.

ROSENBLOOM, B. Canais de Marketing: uma visão gerencial. São Paulo: Atlas, 2002.

VALE, G. M. V. Empreendedores Coletivos em Redes Organizacionais - Novos Agentes Gerando um Padrão Diferenciado de Competitividade. XXVIII ENANPAD (ENCONTRO DA ASSOCIAÇÃO NACIONAL DE PÓS-GRADUAÇÃO E PESQUISA EM ADMINISTRAÇÃO), 2004, Curitiba. Anais..., Curitiba, 2004, cd-rom.

Laços como Ativos Territoriais: análise das aglomerações produtivas na perspectiva do capital social. Tese (Doutorado em Administração). Universidade Federal de Lavras, Lavras, 2006.

ZYLBERSZTAJN, D.; FARINA, E. M. M. Q. Dynamics of Network Governance: a contribution to the study of complex forms. Série de Working Papers. 03/026. FEAUSP, 2003. Disponível em: <www.ead.fea.usp.br/wpapaers>. Acesso em: 05/05/2006.

Recebido em: 19/12/2009.

Aprovado em: 19/01/2010. 